\title{
Progressive degeneration of the right temporal lobe studied with positron emission tomography
}

\author{
P J Tyrrell, E K Warrington, R S J Frackowiak, M N Rossor
}

\begin{abstract}
A 79 year old man with a twelve year progressive history of prosopagnosia and recent naming difficulty, in whom other intellectual skills were preserved, is described. Positron emission tomography (PET) revealed an area of right temporal lobe hypometabolism, with an additional area of less severe hypometabolism at the left temporal pole. This may represent an example of progressive focal cortical degeneration similar to that associated with primary progressive dysphasia, but affecting the right temporal lobe.
\end{abstract}

Progressive, focal cognitive disorders due to localised cortical degeneration, have been described presenting as slowly progressive dysphasia, ${ }^{1}$ and less commonly, as dyspraxia, agnosia, ${ }^{2}$ or visual failure. ${ }^{3}$ The underlying cause, and the course, of these focal degenerations is unclear. They have been reported as both the initial presentation of primary degenerative dementia, and as a selective disorder progressing over many years, without evidence of more generalised cognitive impairment. While one case of focal progressive dysphasia eventually leading to dementia was shown at necropsy to have Pick's disease, ${ }^{45}$ a similar patient, with a more rapid progression to dementia, had the neuropathological features of Alzheimer's disease. ${ }^{6}$ Two further cases, who had no evidence of generalised dementia, showed cortical spongiform degeneration in the absence of Pick bodies, plaques or tangles. ${ }^{7}$ Metabolic studies with PET have shown left temporoparietal hypometabolism in two cases of progressive dysphasia without dementia. ${ }^{8}$

Although focal degenerations may affect other areas of cerebral cortex, involvement of the left temporal lobe is most commonly reported. The reason for this predilection is unknown, and examples of focal right temporal degeneration have not hitherto been reported. One of a series of six focal progressive dysphasia patients ${ }^{9}$ had evidence of minor right hemisphere hypometabolism, affecting particularly the anterior temporal lobe, in addition to the prominent left hemisphere hypometabolism. This patient had the longest history and was the most severely affected, which suggests that the non-dominant temporal lobe may be affected at a late stage.

The following case report describes a patient with a twelve year history of progressive prosopagnosia who had developed a nam- ing deficit at a late stage. The main area of hypometabolism was in the right temporal lobe, with a less severe area in the left temporal lobe. This may represent an example of focal right temporal lobe degeneration.

\section{Case history}

A 79 year old right handed retired pharmacist presented with a progressive history of difficulty in recognising faces. Twelve years before presentation, he first noted impairment of his ability to remember the faces of people well known to him, which had progressed to the extent that he could no longer recognise his immediate family. In addition, for two to three years before presentation, he had difficulty remembering the names of places, and more recently difficulty with the names of friends and siblings and some difficulty naming objects. However, he continued to travel long distances alone, and to play competitive chess.

One half-brother became demented before death in his late eighties; there was no other family history of dementia or neurological disease. The patient's father had had pernicious anaemia. In the past, the patient had suffered a right-sided Bell's palsy. He was on thyroxine replacement for hypothyroidism, and vitamin B12 for pernicious anaemia.

On examination, he appeared very fit. General neurological examination was normal, apart from facial asymmetry without weakness. Speech was fluent with normal articulation, prosody and intonation. There was no evidence of apraxia, or primitive reflexes. General examination was normal, with a blood pressure of 160/90 mm mercury.

Haematological and biochemical investigations were normal, apart from the presence of positive gastric antibodies, and thyroid microsomal antibodies were positive at a titre of $1: 6,400$. Free thyroxine was within normal limits. Cerebrospinal fluid examination was normal, and syphilis serology negative. CT head scan showed minor enlargement of both sylvian fissures, particularly on the right (fig 1).

\section{Neuropsychological assessment}

On the WAIS-R he obtained a verbal IQ of 117 (pro-rated from four subtests), and a performance IQ of 101 (pro-rated from three subtests). On the Coloured Progressive Matrices he obtained a score $(26 / 36$ correct) close to the 75 th percentile. ${ }^{10}$ (His scores on the above two tests are age-corrected). On Raven's Advanced Progressive Matrices Set A 


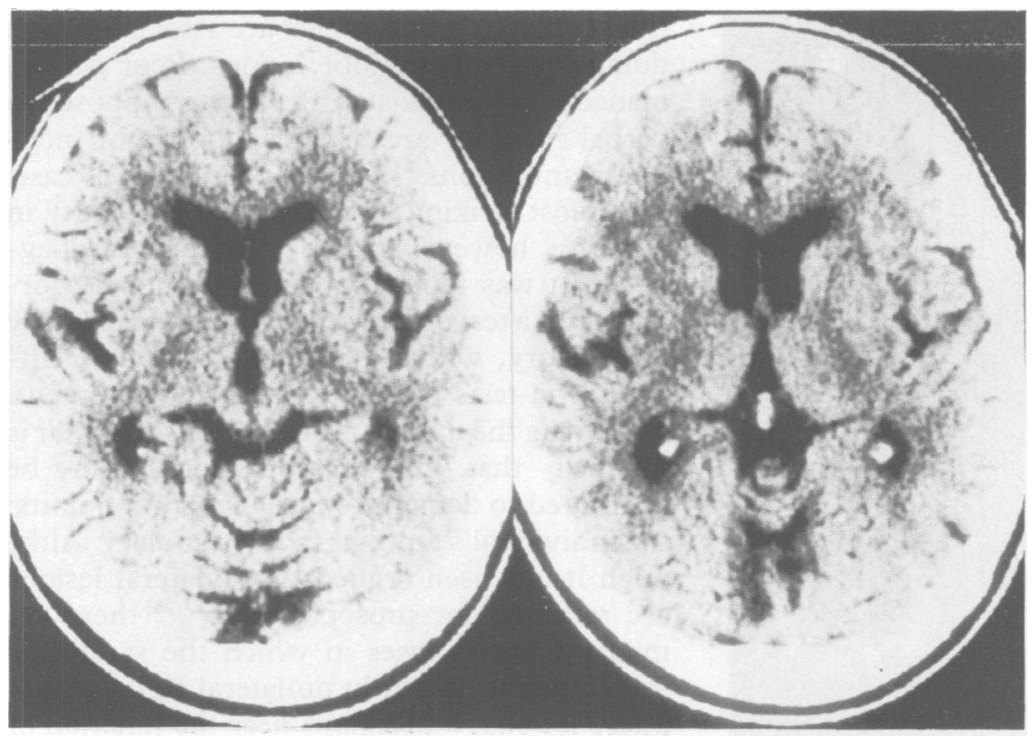

Figure 1 CT head scan of the patient, showing enlargement of both sylvian fissures, most marked on the right. The left hand side of the scan corresponds to the right hemisphere in this figure. which required him to judge whether two photographs were of the same person or not, his score $(16 / 20)$ was just below the 25th percentile. However, he scored at a normal level on the long version of Benton's test of face perception (raw score 43 corrected for age and education) ${ }^{18}$

His most striking deficit was in recognising familiar faces. In identifying famous faces in a set of 12 , he identified only one person (Mrs Thatcher). On a test of face familiarity on which the task is to choose the most famous person from two nonentity distractor stimuli, he obtained an exceptionally poor score $(6 / 30$ correct). On a verbal version of this task he obtained 27/30 correct. $^{19}$ These findings corroborate the difficulty that he has in everyday life in recognising his family and friends by sight. He was considered to have a profound prosopagnosia.

\section{Methods}

15-O steady state positron emission tomography (PET) was performed on the CTI/931/08/ 12 scanner (Knoxville, Tennessee, USA) at the Medical Research Council Cyclotron Unit, Hammersmith Hospital, to obtain regional values of $\mathrm{CMRO}_{2}$ (cerebral metabolic rate for oxygen). Ethical approval for these studies, and for normal studies on eight volunteers (aged 59-83 years; mean 69.3 years), was obtained from the Ethical Committees of St Mary's, the National and Hammersmith Hospitals. Approval to administer radiolabelled gases was obtained from the ARSAC (Administration of Radioactive Substances Advisory Committee of the United Kingdom). Written consent was obtained from all patients and normal volunteers, after a full explanation of the procedure.

All normal subjects had no abnormalities on physical examination, and a normal blood pressure. They scored at least $28 / 30$ on the MiniMental State Examination. ${ }^{20}$ Subjects with a history of seizures, significant head injury, hypertension, or neurological or other systemic disease were excluded. Two of the oldest volunteers (aged 74 and 83 ) had had CT scans performed, as part of another research project, which were normal.

The technique of ${ }^{15}$-O-steady state scanning with correction for cerebral blood volume has been described previously, ${ }^{21-23}$ and was used to obtain parametric images of cerebral metabolic rate for oxygen $\left(\mathrm{CMRO}_{2}\right)$, cerebral blood flow $(\mathrm{CBF})$, oxygen extraction ratio (OER) and cerebral blood volume (CBV).

Images were inspected to ascertain the presence and position of focal deficits. Details of the image analysis technique has been published elsewhere, ${ }^{9}$ but essentially consists of placing standard anatomical stereotactic coordinates based on the Talairach atlas ${ }^{24}$ onto the parametric images, to obtain $\mathrm{CMRO}_{2}$ values for anatomical regions. Areas of hypometabolism in the patient were clearly delineated on the PET scan (fig 2). The regions of interest covered almost the whole width of the cortical ribbon. Visual inspection indicated that the areas of maximal hypometabolism were restric- 


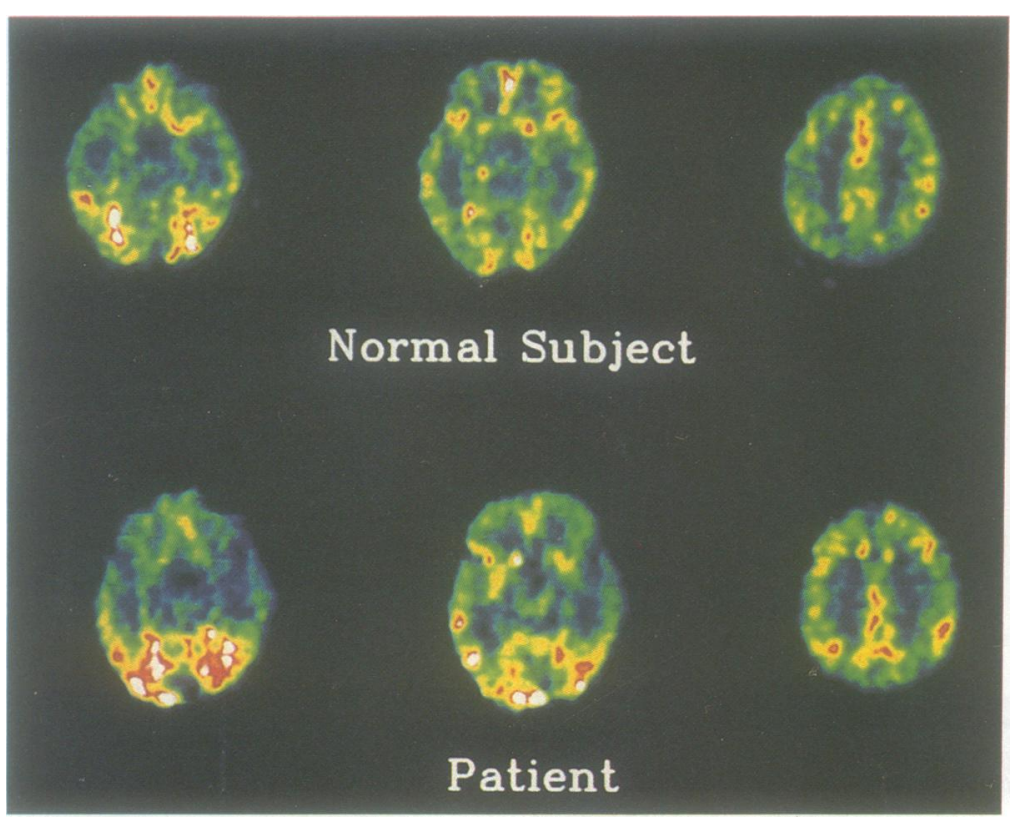

Figure 2 Transverse sections of the patient's CMRO2 scan, with a representative normal scan shown above. On the PET images, the left hemisphere is shown on the left hand side of the scan. The images on the left are $9 \mathrm{~mm}$ below the intercommissural line ( $A C-P C$ line), the central images $2 \mathrm{~mm}$ below the $A C-P C$ line, and the images on the right are $50 \mathrm{~mm}$ above. A bilateral deficit is seen in the anterior temporal lobes of the patient's scan, visible on the lowest image; in the central, higher image the right hemisphere deficit only is clearly visible. In the highest slice, which is through the parietal lobes, no deficit is seen.

ted to the temporal lobes. Regions of interest were therefore placed on the anterior, middle, and posterior frontal gyri, and the superior, middle and inferior temporal gyri in the right and left hemispheres. Each structure was sampled with six regions of interest, from six adjacent anatomical planes. The mean value for each structure is presented. In addition, cerebellar cortex was sampled from two lower planes, and anterior and posterior parietal cortex from two representative planes through superior cuts distant from the visible sites of hypometabolism. Occipital cortex was sampled in three areas from three planes. Measurements were made from the left and right hemispheres independently.

\section{Results}

Regional values of $\mathrm{CMRO}_{2}$ showed significant reductions in the superior temporal gyrus on both sides, more marked on the right than on the left; right: $1.47 \mathrm{ml} / \mathrm{min} / \mathrm{dl}$ (mean value for the eight normal volunteers $2.76 \mathrm{ml} / \mathrm{min} / \mathrm{dl}$, standard deviation 0.41 ); left: $1.81 \mathrm{ml} / \mathrm{min} / \mathrm{dl}$ (mean value for the eight normal volunteers $2.74 \mathrm{ml} / \mathrm{min} / \mathrm{dl}$, standard deviation 0.40 ). Values for middle and inferior temporal gyri, frontal cortex, parietal cortex, occipital cortex, cerebellum, and thalamus, caudate and putamen were within the normal range bilaterally.

Figures 2 and 3 show the $\mathrm{CMRO}_{2}$ images of the patient, and a normal for comparison.

\section{Discussion}

The main area of hypometabolism relates to the right anterior temporal lobe, specifically in the right superior temporal gyrus. Clinical abnormalities arising from lesions of the non-dominant temporal lobe are often less apparent than the language deficits which are associated with dominant temporal lobe lesions. Poor performance on tasks of visual memory, as opposed to verbal memory are usually found with nondominant lesions ${ }^{12}{ }^{25}$ as was found in this case. The most striking and earliest abnormality in our case, however, was a profound prosopagnosia. It was found that the patient's performance on a test of face perception was relatively satisfactory, whereas he had exceptional difficulty on tests of face familiarity judgement. Following the model of Bruce and Young ${ }^{26}$ it is inferred that his prosopagnosia can be attributed to damage to face recognition units: the individual's familiar face vocabulary. Although it has been argued that bilateral lesions are required for prosopagnosia, ${ }^{27}$ there are many reported cases in which the syndrome arises from apparently unilateral right hemisphere lesions. ${ }^{29-31}$ Regions near the junction of temporal, occipital and parietal lobes are usually implicated, that is, more posterior than the area of maximal hypometabolism observed in our patient. In addition, the poor performance on visual perceptual tasks suggests an additional parietal lobe deficit not readily apparent on the $\mathrm{CMRO}_{2}$ scan. Although a lesion in this area is indeed frequently implicated in cases of prosopagnosia, our findings raise the possibility that a prosopagnosia in which recognition mechanisms of familiarity are involved, (perceptual analysis of faces being preserved), may arise from a more anterior lesion.

The area of hypometabolism in the left anterior temporal lobe, associated with the observed nominal dysphasia in the presence of normal comprehension, is entirely consistent with data that implicates the left temporal lobe in word retrieval skills. ${ }^{32}{ }^{33}$ The involvement of the left superior temporal gyrus alone, with preservation of the rest of the left temporal lobe, is also consistent with the findings of a common area of hypometabolism in the left superior temporal gyrus in the six cases with focal progressive dysphasia characterised by a naming deficit reported previously. ${ }^{9}$ The least affected of these patients, with a pure naming deficit, had hypometabolism restricted to this area.

The anatomical symmetry of the hypometabolism is of interest, with the most profound abnormality in the superior temporal gyrus on the right, and the only area of abnormality on the left confined to the superior temporal gyrus. This could be due to transcallosal connections, providing a route for transfer of a pathogenic agent. Alternatively, it may reflect selective vulnerability of the anterior temporal cortex to an unknown pathogenic agent or process. The most advanced case of primary progressive dysphasia reported previously ${ }^{9}$ showed a small area of hypometabolism in the right temporal lobe, in addition to severe hypometabolism in the left hemisphere.

The underlying aetiology of patients with progressive focal disorders is not known, but the very long progressive history in a normotensive man, and the absence of vascular lesions 
Figure 3 Coronal sections of the patient's CMRO2 scan, with a representative normal scan shown above. The right temporal lobe abnormality is visible inferiorly on the right hand side of the patient's images.

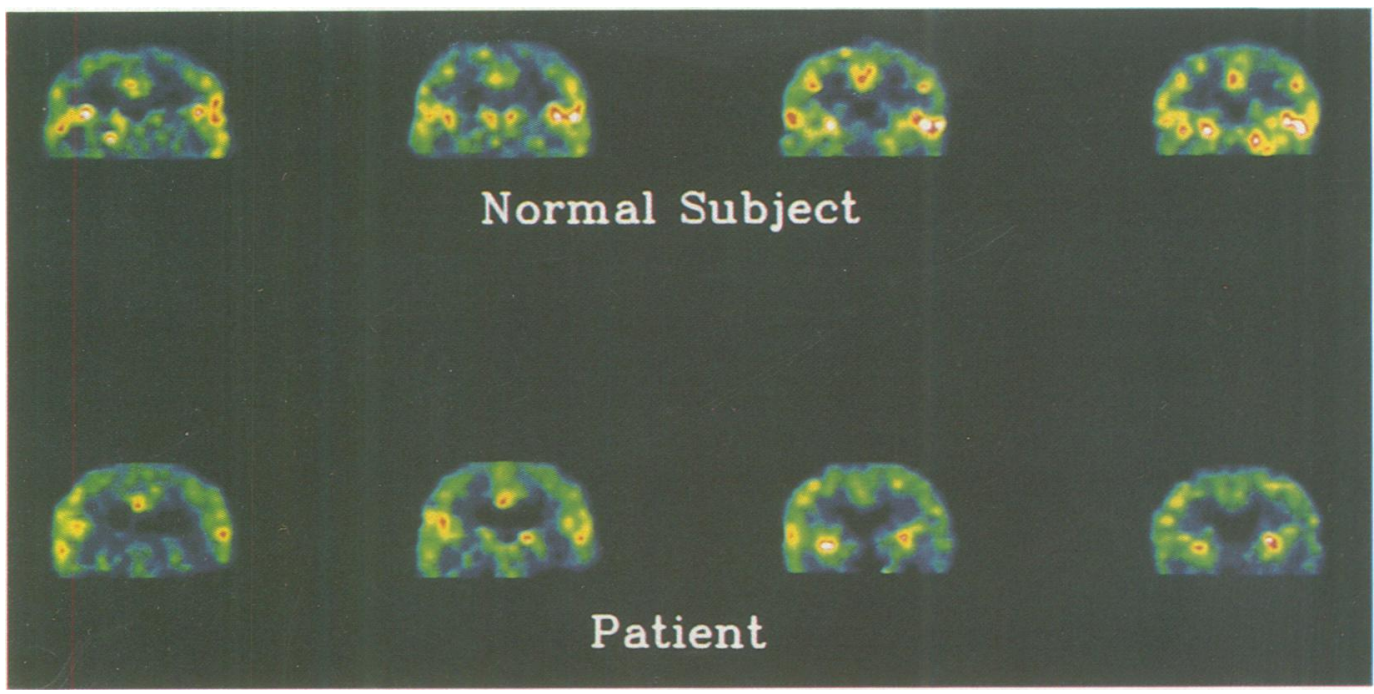

on CT scan, argues in favour of a degenerative process. While Alzheimer's disease may present as a progressive dysphasia ${ }^{6}$ or as cortical blindness, ${ }^{34}$ the disease progresses rapidly to a generalised dementia. In addition, the PET scan in our patient did not show the posterior biparietal and bitemporal hypometabolism associated with dementia of the Alzheimer type,$^{35}$ and the EEG was normal, in contrast to the slow wave abnormality usually seen in Alzheimer's disease.

Other cortical degenerations that may present as focal progressive cognitive disorders include Pick's disease, ${ }^{5}$ and unilateral Creutzfeld-Jakob disease. ${ }^{36}{ }^{37}$ The underlying pathology may be similar to that described in cases of focal progressive dysphasia by Kirshner et $a l,{ }^{7}$ with focal spongiform degeneration.

While a number of cases of left temporal lobe degeneration have been described, ${ }^{138}$ right temporal lobe degeneration has not previously been reported. This may be due to selective vulnerability of the left temporal lobe, or that language disturbance is more clinically apparent. It is noteworthy that the symptom which brought this patient to medical attention was the relatively recent onset of difficulty with object naming.

This case underlines the clinical and anatomical heterogeneity of the focal progressive cognitive degenerations, which presumably reflects heterogeneity of the underlying pathological processes.

We are grateful to Professor Brice-Pitt, Hammersmith Hospital, for permission to study one of his patients. We are indebted to Dr M Jackson and Dr F Clegg, of the Department of Neuropsychology, The National Hospital, who undertook the neuropsychological assessments. We thank Miss Claire Taylor, and our colleagues in the Chemistry and Physics sections of the MRC Cyclotron Unit who made this study possible. This study was partly funded by an MRC project grant.

1 Mesulam M-M. Slowly progressive aphasia without generalised dementia. Ann Neurol 1982;11:592-8.

2 de Renzi E. Slowly progressive visual agnosia or apraxia without dementia. Cortex 1986;22:171-80

3 Benson DF, Davis RJ, Snyder BD. Posterior cortical atrophy. Arch Neurol 1988;45:789-93.

4 Wechsler AF. Presenile dementia presenting as aphasia. $J$ Neurol Neurosurg Psychiatry 1977;40:303-5.

5 Wechsler AF, Verity A, Rosenschein S, Fried I, Scheibel
AB. Pick's disease: a clinical, computed tomographic and Arch Neurol 1982;39:287-90.

6 Pogacar S, Williams RS. Alzheimer's disease presenting as slowly progressive aphasia. Rhode Is Med J 1984;67: 181-5.

7 Kirshner HS, Tanridag O, Thurman L, Whetsell WO. Progressive aphasia without dementia: two cases with focal spongiform degeneration. Ann Neurol 1987;22. 527-32. progressive aphasia without generalised dementia: studies with positron emission tomography. Ann Neurol 1986; with posito

9 Tyrrell PJ, Warrington EK, Frackowiak RSJ, Rossor MN Heterogeneity in progressive aphasia due to focal cortical atrophy: A clinical and PET scan study. Brain 1990;113 1321-36.

10 Raven JC. Coloured progressive matrices. London: HK Lewis, 1956.

11 Nelson HE. The National Adult Reading Test. Windsor, Berkshire: NFER, 1982.

12 Warrington EK. Recognition Memory Test. Windsor, Berkshire: NFER, 1984.

13 Dunn ML, Dunn LM, Whelton C, Pintille D. British Picture Vocabulary Scale. Windsor, Berkshire: NFERNelson, 1982 .

14 Oldfield RC, Wingfield A. Response latencies in naming objects. Quart J Exp Psychol 1965;17:272-81.

15 McKenna P, Warrington EK. The Graded Naming Test. Windsor, Berkshire: NFER-Nelson, 1983.

16 Warrington EJ, James M. Visual apperceptive agnosia: a clinico-anatomical study of three case. Cortex 1988;24 13-32.

17 Warrington EK. Visual deficits associated with occipital lobe lesions in man. Vatican symposium "Pattern Recognition Mechanisms". In: C Chagas, R Gattas, C Gross, eds. Pontificiae Academiae Scientiarvum Scripta Varia $1988 ; 54: 247-61$

18 Benton $A L$, Van Allen MW. Impairment in facial recognition in patients with cerebral disease. Cortex 1968;4: 344-58.

19 Warrington EK, McCarthy RA. Fractionation of retrograde amnesia. Brain and Cognition 1988;7:184-200.

20 Folstein MF, Folstein SE, McHugh PR. Mini-mental state: a practical method for grading the cognitive state of patients for the clinician. J Psychiatr Res 1976;12:189-98.

21 Frackowiak RSJ, Lenzi G-L, Jones T, Heather JD. Quantitative measurement of regional cerebral blood flow and oxygen metabolism in man using ${ }^{15} \mathrm{O}$ and positron emission tomography: theory, procedure and normal values. $J$ Cereb Blood Flow and Metab 1980;4:727-36.

22 Lammertsma AA, Jones T. Correction for the presence of intravascular oxygen-15 in the steady-state technique for measuring regional oxygen extraction ratio in the brain: 1 . Description of the method. J Cereb Blood Flow and Metab 1983;3:416-24.

23 Lammertsma AA, Wise RJS, Heather JD, et al. Correction for the presence of intravascular oxygen-15 in the steadyfor the presence of intravascular oxygen-15 in the steadystate technique for measuring regional oxygen extraction ratio in the brain: 2 . Results in normal subjects and brain
tumour and stroke patients. $J$ Cereb Blood Flow and Metab tumour and stroke

24 Talairach J, Szikla G, Tournoux P, et al. Atlas d'Anatomie Stereotaxique du Telencephale. Paris: Masson et Cie, 1967. 25 Milner B. Visual recognition and recall after right tempora lobe excision in man. Neuropsychologia 1968;6:191-209. Psychology 1986;77:305-27. anatomic basis and behaviour mechanisms. Neurology 1982;32:331-41. histologic study with golgi impregnation observations.

8 Chawluk JB, Mesulam M-M, Hurtig H, et al. Slowly

26 Bruce V, Young AW. Understanding face recognition. Brit

27 Damasio AR, Damasio H, Van Hoesen GW. Prosopagnosia: 
28 Damasio AR, Damasio $H$. The anatomical substrate of prosopagnosia. In: R Bruyer, ed. The neuropsychology of face perception and facial expression. Hillsdale, $\mathrm{NJ}$ :

29 Whiteley AM, Warrington EK. Prosopagnosia: a clinical and anatomical study of three patients. J Neurol Neurosurg Psychiatry 1977;40:395-403.

30 de Renzi E. Prosopagnosia in two patients with CT scan evidence of damage confined to the right hemisphere. Neuropsychologia 1986:24:385-9.

31 Landis T, Regard M, Blietle A, Kleihues P. Prosopagnosia and agnosia for noncanonical views. Brain 1988;111: 1287-97.

32 Kertesz A, Harlock W, Coates R. Computer tomographic localisation, lesion size, and prognosis in aphasia and nonverbal impairment. Brain and Language 1979;8:34-50.

33 Coughlan AK, Warrington EK. Word-comprehension and word-retrieval in patients with localised cerebral lesions. Brain 1978;101:163-85.

34 Faden AI, Townsend JJ. Myoclonus in Alzheimer's disease A confusing sign. Arch Neurol 1976;33:278-80.

35 Frackowiak RSJ, Pozzilli C, Legg NJ, du Boulay GH, Marshall J, Lenzi GL Jones T Regional ceral GH, supply and utilisation in dementia A clinical and physiological study with oxygen-15 and positron tomography. Brain 1981;104:753-78.

36 Yamanouchi H, Budka H, Vass K. Unilateral CreutzfeldJakob Disease. Neurology 1986;36:1517-20.

37 Mandell AM, Alexander MP, Carpenter S. CreutzfeldJakob disease presenting as isolated aphasia. Neurology 1989;39:55-8.

38 Poeck K, Luzzati C. Slowly progressive aphasia in three patients: the problem of accompanying neuropsychological deficit. Brain 1988;111:151-68. 